\title{
Evaluation of causes of acute hip pain in children at Erbil teaching hospital
}

\author{
Zohair M. Al-Saffar *, Sherwan J. Shareef ** \\ * Department of Surgery, College of Medicine, Hawler Medical University; \\ ** Department of Surgery, Erbil Teaching Hospital, Erbil.
}

(Ann. Coll. Med. Mosul 2011; 37 (1 \& 2): 103-109).

Received: $14^{\text {th }}$ Dec 2010; Accepted: $10^{\text {th }}$ Oct 2011.

\begin{abstract}
Objectives: Painful hip in children is a common pediatric problem and there are several causes for hip pain. In this study we will show the most common causes of hip pain in children and evaluate the procedures performed at our hospital, with a view of establishing which parameters most relevant to make a clinical decision.

Methods: This is a case review study which was carried out at Erbil Teaching Hospital between December 2006 and October 2007. Sixty two patients who had consultations and/or been admitted at our hospital complaining of hip pain were included in this study. We did investigations for them and we reviewed their clinical, laboratory and imaging documents.

Results: The differential diagnosis was transient synovitis (TS) $54.8 \%$, Legg-Calves-Perthes disease $24.2 \%$, septic arthritis (SA) $8.1 \%$, traumatic synovitis $4.8 \%$, avulsion fractures $3.2 \%$, brucellosis $1.6 \%$, tuberculosis $1.6 \%$, and non specific synovitis $1.6 \%$. We found that three or more criteria,(the clinical and laboratory parameters), were present in all cases of septic arthritis (100\% sensitivity), but also were present in $10 \%$ of non septic conditions ( $90 \%$ specificity). Radiographs showed abnormalities in $50 \%$ of the cases. Ultrasound showed joint effusion in 43 patients with $100 \%$ of sensitivity.

Conclusions: Transient synovitis is the most common cause of irritable hip. Application of our scheme might result in a reduction of the number of patients who need hospital admission and also reduction of invasive procedures and containment of the cost.
\end{abstract}

Keywords: Diagnosis of painful hip.

\section{الخلاصة}

الههف: تتخيص أهم أسباب الآم مفصل الورك لدى الأطفال مع تقييم الطرق العلاجية المتبعة في المستشفى لإيجاد أكثر

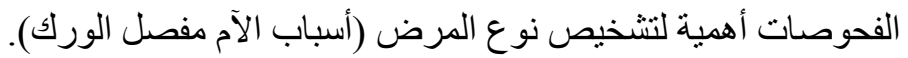

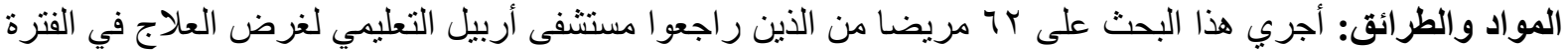

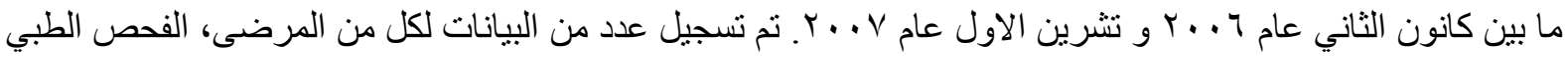

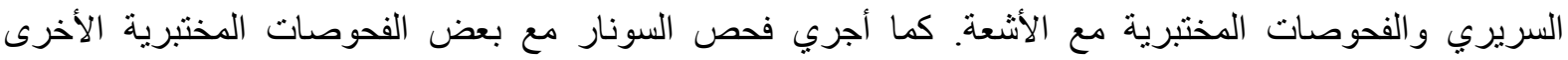

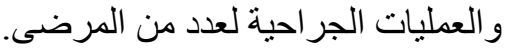

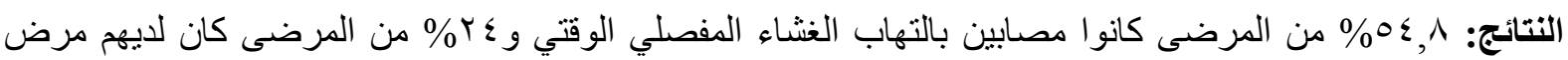

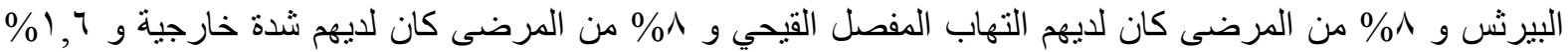

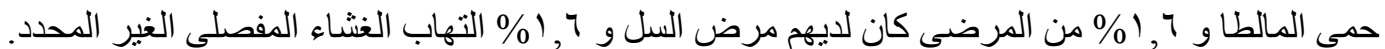

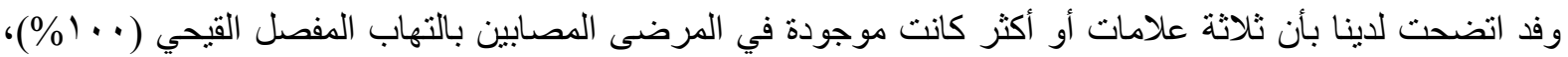
ولكن كانت موجودة أيضا في (• (1\%) من المرضى الآخرين. 


$$
\begin{aligned}
& \text { الأشعة كانت طبيعية في (•0\%) من المرضى و تورم مفصل الحوض وجدت في (T؟) مريضا بو اسطة فحص السونار. }
\end{aligned}
$$

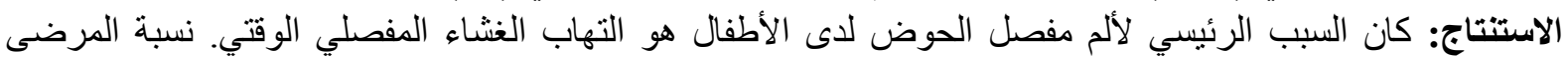

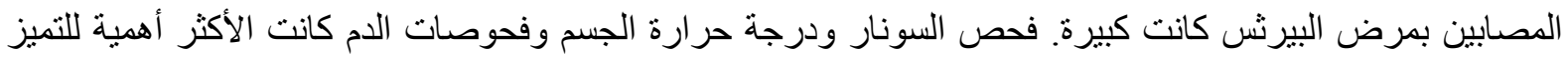

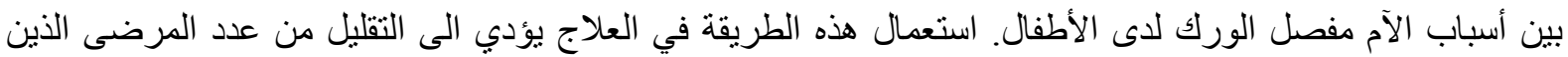

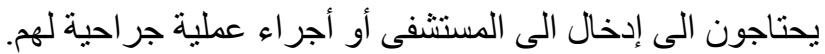

$\mathrm{T}$ he causes of painful hip may include numerous disorders ${ }^{(1)}$. Some of these conditions are benign and self-limiting disorder, like transient synovitis ${ }^{(2,3)}$. On the other hand, septic arthritis is a medical emergency that needs rapid confirmation and treatment and usually hospital admission ${ }^{(3,4)}$. Because early treatment is the single most important prognostic factor for a favorable outcome; therefore, a fast and reliable investigation scheme for irritable hips is mandatory; which, for feasibility, should be based on simple, affordable, and non-invasive medical techniques.

Various strategies for the work-up of children with hip pain have been proposed, some of them were based on clinical signs and laboratory parameters ${ }^{(3,4)}$ while others relied more on medical imaging and aspiration of the hip joint ${ }^{(2-9)}$. Imaging was usually performed with ultrasound and radiography. Other modalities, such as bone scintigraphy, computed tomography, and magnetic resonance imaging, although were used by some authors ${ }^{(10)}$, were not routinely used for primary evaluation of painful hips ${ }^{(5,6,11)}$.

In this study we depended mainly on clinical signs and symptoms, simple laboratory tests, radiography and ultrasound, aiming to identify the most common causes of hip pain in patients who presented to our hospital; and to evaluate the procedures which are performed at our hospital with a view to establish which parameters are most relevant to make a clinical decision.

\section{Material and methods}

Sixty two patients were included in this study; their ages ranged 2-13 year. For each patient we recorded the duration of signs and symptoms, limping or inability to walk, hip or knee pain (referred pain) and temperature. All patients had a standard anterior-posterior radiograph of the pelvis, with an additional lateral or oblique view of the affected hip, erythrocyte sedimentation rate (ESR), C-reactive protein (CRP), white cell count and hemoglobin concentration. Brucella agglutination test and latex slide agglutination test were done for some patients according to their presentation.

Ultrasound was performed for patients with negative, or positive but not conclusive, radiological findings regardless of the results of laboratory tests of the patient (i.e. ultrasonography was not done for patients with positive $x$-ray findings because of the conclusive diagnosis reached.

Patients in whom septic arthritis of the hip was suspected, based on their clinical presentation and laboratory findings, and who had effusion shown on ultrasound, were subjected to arthrotomy (surgical drainage) performed under general anesthesia. A sample of joint aspirate was taken for bacteriological study. The appearance of the aspirate and the results of the bacteriological tests were recorded.

After performing all investigations, radiographs and follow up, the diagnosis was not certain in two patients, so we proceeded for synovial biopsy. The histopathological results of the biopsies were recorded.

Diagnosis was made if the following criteria were met:

- Septic arthritis: presence of signs and symptoms (fever, joint swelling, tenderness on local examination and limited movement), positive laboratory tests (high erythrocyte sedimentation rate (E.S.R.), positive C-reactive protein (CRP), leucocytosis, and low hemoglobin concentration), joint effusion on ultrasound, and pus was drained from the 
hip joint, a sample of joint aspiration was taken for bacteriological study. The appearance of aspirate and the result of the bacteriological testes were recorded.

- Perthes disease: the radiographs showing characteristic features and evolution of sclerosis, subchondral fracture, fragmentation, and flattening of the femoral head during the follow up.

- Transient synovitis is certain when joint effusion demonstrated by ultrasound with normal laboratory tests, no bony changes on x-ray and uneventful recovery during follow up.

- Trauma: is put as a diagnosis when the patient had a history of recent trauma and laboratory tests were normal with effusion which is shown by ultrasound or positive radiography.

- Other causes: this group included patients with data not fit with criteria of diseases mentioned above, so further blood tests and synovial biopsy were done.

The following conditions were excluded: Major trauma with fractures of the proximal femur and the hip, referred pain from the spine, femoral head and neck deformity, already diagnosed or old cases, and developmental dysplasia of the hip.

Fisher's exact test was used in statistical analysis. Fisher's exact test a statistical significance test used in the analysis of contingency tables where sample sizes are small. $P$ value significant when $p<0.001$.

\section{Results}

The age of patients ranged from 2-13 year, with an average of 5.5 year. There was no patient with bilateral hip involvement.

The causes of hip pain are shown in (table 1) which shows high percentage of hip pain in children caused by transient synovitis in 34 patients $(54.8 \%)$. Fever was present in 12 patients (table 1). The average temperature was (38.2 C). The degree of the fever was mild in cases of TS, tuberculosis and brucellosis with a range of (37.6 C) to (37.9 C), and it was moderate to high fever in cases of SA with a range of $(38.6 \mathrm{C})$ to $(39.3 \mathrm{C})$. Fever was present in all patients with septic arthritis $(p<0.001$ by Fisher's exact test). WBC count $\geq 10 \times 10^{9} / \mathrm{L}$ was found in 9 patients $(14.5 \%)$, five patients had transient synovitis and four patients had septic arthritis. The average was $7.5 \times 10^{9} \mathrm{IL}$. ESR $\geq 10 \mathrm{~mm} / \mathrm{hr}$ found in 36 patients (table 1), the average was 20.2 $\mathrm{mm} / \mathrm{hr}$. ESR $>10 \mathrm{~mm} / \mathrm{hr}$ found in $54 \%$ of the cases so, it is not significant parameter $(p=.068$ by Fisher's exact test). CRP was positive in $11.3 \%$ of cases (table 2), it is an acute phase reactant protein, and it is a good tool to differentiate septic from non septic cases ( $P$ value is missed because $n$ is small). Brucella agglutination test was positive in one case with a titer of $1 / 320$. Anemia was found in three children only, one with tuberculosis and the other two with transient synovitis.

Table (1): Differential diagnosis of hip pain and prevalence of fever and ESR level more than 10 $\mathrm{mm} / \mathrm{hr}$.

\begin{tabular}{|l|c|c|c|c|c|}
\cline { 2 - 6 } \multicolumn{1}{c|}{} & \multicolumn{1}{c|}{$\begin{array}{c}\text { Differential diagnosis } \\
\text { of hip pain }\end{array}$} & \multicolumn{2}{c|}{ Prevalence of fever } & \multicolumn{2}{c|}{$\begin{array}{c}\text { E.S.R. } \\
\text { Level more than10 } \mathrm{mm} / \mathrm{hr}\end{array}$} \\
\hline \multicolumn{1}{|c|}{ Diagnosis } & No. of patient & Yes & No & $<10$ & $>10=$ \\
\hline Transient synovitis & $34(54.8 \%)$ & $5(14.7 \%)$ & $29(85.3 \%)$ & $8(23.5 \%)$ & $26(76.5 \%)$ \\
\hline Perthes disease & $15(24.2 \%)$ & 0 & $15(100 \%)$ & 0 & $5(100 \%)$ \\
\hline Septic arthritis & $5(8.1 \%)$ & $5(100 \%)$ & 0 & 0 & $5(100 \%)$ \\
\hline Traumatic synovitis & $3(4.8 \%)$ & 0 & $3(100 \%)$ & $2(66.7 \%)$ & $1(33.3 \%)$ \\
\hline Avulsion injuries & $2(3.2 \%)$ & 0 & $2(100 \%)$ & $2(100 \%)$ & 0 \\
\hline brucellosis & $1(1.6 \%)$ & $1(100 \%)$ & 0 & 0 & $1(100 \%)$ \\
\hline tuberculosis & $1(1.6 \%)$ & $1(100 \%)$ & 0 & 0 & $1(100 \%)$ \\
\hline Non specific synovitis & $1(1.6 \%)$ & 0 & $1(100 \%)$ & 0 & $1(100 \%)$ \\
\hline Total & $62(100 \%)$ & & & $26(41.9 \%)$ & $36(58.1 \%)$ \\
\hline
\end{tabular}


Table (2): Cases with positive C-reactive protein and Radiological findings.

\begin{tabular}{|l|c|c|c|c|c|}
\hline & \multicolumn{2}{|c|}{$\begin{array}{c}\text { Case with positive C- } \\
\text { reactive protein }\end{array}$} & \multicolumn{3}{c|}{ X-ray findings } \\
\hline \multicolumn{1}{|c|}{ Diagnosis } & - ve & + ve & No change & Bony chg. & Wide J. space \\
\hline Transient synovitis & $32(94.1 \%)$ & $2(5.8 \%)$ & $28(82.4 \%)$ & 0 & $6(17.6 \%)$ \\
\hline Perthes disease & $15(100 \%)$ & 0 & 0 & $15(100 \%)$ & $15(100 \%)$ \\
\hline Septic arthritis & 0 & $5(100 \%)$ & $2(40 \%)$ & $1(20 \%)$ & $2(40 \%)$ \\
\hline Traumatic synovitis & $3(100 \%)$ & 0 & $1(33.3 \%)$ & 0 & $2(66.7 \%)$ \\
\hline Avulsion injuries & $2(100 \%)$ & 0 & 0 & $2(100 \%)$ & 0 \\
\hline brucellosis & $1(100 \%)$ & 0 & 0 & $1(100 \%)$ & 0 \\
\hline tuberculosis & $1(100 \%)$ & 0 & 0 & $1(100 \%)$ & 0 \\
\hline Non specific synovitis & $1(100 \%)$ & & 0 & $1(100 \%)$ & 0 \\
\hline Total & $55(88.7 \%)$ & $7(11.3 \%)$ & $31(50 \%)$ & $6(9.7 \%)$ & $10(16.1 \%)$ \\
\hline
\end{tabular}

Radiographs were abnormal in 31 patients in the form of widening of the joint space (indirect evidence of the joint effusion), bony changes or both of them. The bony changes were one or more features of sclerosis, fragmentation, subchondral fractures and flattening of the femoral head, irregular bony contour with rarefaction and subchondral cystic changes. In 31 patients the radiographs were normal (table 2).

Total number of patients who had an ultrasound was 44 . Joint effusion was found in all cases except in one patient.

History of recent trauma was present in five cases $(8.1 \%)$, while six more patients $(9.6 \%)$ gave the history of trauma within the last few months before the time of the presentation. Arthrotomy was done in seven patients $(11.3 \%)$. In two cases the synovial fluid was non purulent and synovial biopsy was performed. The histopathological study showed tuberculosis in one case and non specific synovitis in the other. Purulent Synovial fluid was found in 5 cases. The result of culture was positive in all except in one patient who received antibiotics preoperatively (table 3). We had fortunately no complications from this procedure.
Table (3): Synovial fluid culture.

\begin{tabular}{|l|c|c|}
\hline \multirow{2}{*}{ Type of bacteria } & \multicolumn{2}{c|}{ No. of patients } \\
\cline { 2 - 3 } & No. & $\%$ \\
\hline S. aureus & 3 & 60 \\
\hline H. influenza & 1 & 20 \\
\hline Negative & 1 & 20 \\
\hline Total & 5 & 100 \\
\hline
\end{tabular}

\section{Discussion}

In patients who had Legg-Calve-Perthes disease, female to male ratio was $1: 4$ and this ratio was near to other studies ${ }^{(12-14)}$.

Most of the patients were suffering transient synovitis (54.8\% of the cases), and this was in agreement with other studies ${ }^{(13-15)}$. In our study $(14.7 \%)$ of the cases had mild fever, elevated ESR (41.9\%) and high WBC count; while widening of the joint space on radiographs was found in 6 patients (17.6\%). These are in agreement with some studies ${ }^{3,15-}$ ${ }^{19)}$, and disagreement with others ${ }^{(14)}$.

Legg-Calve-Perthes disease was present in $24 \%$ of the cases; this is higher than in other studies which showed the prevalence of Perthes disease as $4 \%$ of hip pain with a range of $1.5-5 / 10000{ }^{(1)}$, and one in 10,000 ${ }^{(15)}$. There was no patient with bilateral Perthes disease which might be seen in approximately $12 \%$ of cases ${ }^{(13)}$. Probably because of short duration of our study since bilateral perthes disease is usually at different stage of the disease. 
In septic arthritis, the average age of patients was 3.8 years like in other studies ${ }^{(19)}$ (because children in this age are active and they frequently get trauma) which state that overall average age of patients with septic arthritis is 3-6 years. Elevated CRP and ESR were found in all cases $(100 \%)$, other studies showed elevated CRP and ESR in at least $95 \%$ of cases ${ }^{(20)}$. The anterior approach was applied for joint drainage which is the procedure of choice in children ${ }^{(12,21)}$.

Traumatic synovitis was seen in three patients in whom the hip pain was related to a recent accident or trauma, and other clinical and laboratory parameters were normal, except hip effusion on U/S; as in other studies (22)

Avulsion fracture injuries of hip adductors were found in two cases that had history of trauma, one of them also had ecchymosis. Xray findings were seen immediately in one but, after ten days in the other. like other studies $^{(16)}$.

Brucellosis was found in one patient who had hip pain with positive brucella agglutination test. Brucella agglutination test is significant when there is a titer of $1 / 320$ or four fold rising of the titer ${ }^{(23)}$.

Tuberculosis should be considered in the differential diagnosis of arthritis and chronic osteomyelitis specially in patients from endemic area ${ }^{(12)}$. We found a case of tuberculosis and fortunately, we confirmed the diagnosis by synovial biopsy, which is helpful in establishing the diagnosis ${ }^{(12,22)}$.

Non specific synovitis was found in one patient who had atypical clinical and laboratory characteristics and the result of the biopsy showed non specific inflammatory cells. WBC count was more than $10 \times 10^{9} / 1$ in five cases with transient synovitis and in four patients with septic arthritis $(p=0.002)$. These results are in agreement with other studies ${ }^{(2,8)}$. We found that three or more criteria were present in all cases of septic arthritis (100\% sensitivity), but these criteria (pain, fever, elevated W.B.C., elevated E.S.R., elevated CRP) were found also in $10 \%$ of non septic conditions $(90 \%$ specificity. This agreed with other studies which identified four important, independent, diagnostic variables: fever, nonweight bearing on the affected limb, ESR $40 \mathrm{~mm} / \mathrm{hr}$ and WBC count of $\geq 12 \times 10^{9} / 1$, when present together, it is $99.6 \%$ sensitive for diagnosis of septic arthritis of the hip, and $93 \%$ for those with 3 factors ${ }^{(12,17)}$. Also it agreed with investigation schemes based on clinical examination and laboratory tests (ESR and complete blood count) which identified patients with a septic arthritis of the hip with a sensitivity of up to $97 \%$ but had a relatively low specificity which resulted in a large number of hospital admissions ${ }^{(2,6,8)}$. Anemia was present in three patients, one patient with tuberculosis and the other two patients had non specific or nutritional anemia.

According to our results, radiographs showed changes in $50 \%$ of the patients and these changes were not specific in all conditions; therefore, radiography was not a significant parameter. Our study agrees with other reportes ${ }^{(24)}$. An exception to this, radiographs were highly significant in cases of Legg-Calve -Perthes disease who had long-lasting symptoms (more than two to three weeks) and in cases of trauma. This agreed with other studies ${ }^{(24)}$.

Ultrasound detected hip joint effusion in 43 cases with a sensitivity of $100 \%$, like other authors who had $95 \%$ to $100 \%$ sensitivity ${ }^{(7)}$. Other studies reported lower results ${ }^{(9,11)}$. Ultrasound only detected the presence of effusion without prediction of the nature of the effusion whether it is blood or fluid, but it could show whether the fluid contains debris or not and also the presence of cartilage thickening but actually it needs experience. Ultrasound guided joint aspiration had been done in some studies $^{(17,18)}$, but, unfortunately, we could not perform this procedure in our study, because our patients do not accept to be operated twice (one operation for joint aspiration and a second operation for drainage), and because the ultrasound guided joint aspiration is invasive and can occasionally cause complications, so we do not support routine aspiration in patients with hip joint effusion as proposed by some authors ${ }^{(7,22)}$.

Synovial fluid culture was done for five patients, in three cases $(60 \%)$ the result of 
culture and sensitivity was $\mathrm{S}$. aureus, in one case was $\mathrm{H}$. influenza and it was negative in one case who received preoperative antibiotics. This result is identical to other authors ${ }^{(14,20)}$.

In conclusion, transient synovitis is the most common cause of painful hip, and the patient may have mild fever and elevation of WBC count and ESR. There was high incidence of Legg-Calve-Perthes disease. Hip ultra sound, temperature, E.S.R. \& CRP were the most relevant parameters for diagnosing and differentiating possible septic and non-septic effusions of the hip. Avoid unnecessary and expensive investigations for large number of population with simple and benign disorder.

Finally, application of our scheme might result in a reduction of number of patients who need joint aspiration, hospital admission, and imaging, and also reduction of invasive procedures and containment of the cost.

\section{Refrences}

1. Spahn G, Schiele R, Jung R. Hip pain in adolescents: results of a cross sectional study in German pupils and review of the literatures. Acta paediatrica J. 2005;60: 568-571.

2. Taylor GR, Clarke NMP. Management of irritable hip: a review of hospital admission policy. Arch Dis Child J 1994; 71 :59-63.

3. Thompson GH, Scoles P, Behrman RE, Kliegman RM, Arvin AM. Nelson textbook of pediatrics, $17^{\text {th }}$ edition. W.B. Saunders, Philadelphia, 2007; 1937-1942.

4. Narasimhan N, Marks M. Osteomyelitis and septic arthritis. Behrman RE, Kliegman RM, Arvin AM, eds. Nelson textbook of pediatrics. $17^{\text {th }}$ edition. W.B. Saunders, Philadelphia 2007; 724- 733.

5. Bickerstaff R, Neal LM, Brennan PO, Bell MJ. An investigation into the etiology of irritable hip. Clinical Pediatric J 1991; 30:353-56.

6. Del Beccaro MA, Champoux AN, Bockers $T$, Mendelman PM. Septic arthritis versus transient synovitis of the hip: the value of screening laboratory tests. An Emerg Med J. 1992; 21:1418-1422.

7. Fink AM, Berman L, Edwards D, Jacobson SK. The irritable hip: immediate ultrasound guided aspiration and prevention of hospital admission. Arch Dis Child J. 1995; 72: 110-113.

8. Klein DM, Barbera C, Gray ST, Spero CR, Perrier G, Teicher JL. Sensitivity of objective parameters in the diagnosis of pediatric septic hips. Clin Orthop J. 1997; 338:153-159.

9. Wainwright $A M$, Benson MKD. LeggCalve-Perthes' disease. Current orthopedics J. 2001; 15:127-34.

10. Gopakumar TS, Vaishya R, Klenerman L, Carty $\mathrm{H}$. The role of ultrasound and isotope scanning in the management of irritable hips. Eur Radiology J.1992; 15: 113-117.

11. McGoldrick F, Bourke T, Blake N, Fogarty $E$, Dowling $F$, Regan B, Accuracy of sonography in transient synovitis. Pediatric Orthop J. 1990;10:501-303.

12. Vaccaro R. Orthopedic Knowledge Update. $9^{\text {th }}$ edition USA; American Academy of Orthopedic Surgeons (2009) 738-739.

13. MacEwen, G.Dean, Dehne R. The limping child. Pediatrics in review. 1991;12(9): 269- 270.

14. Solomon L, Warwick D, Nayagam S. Apley's system of orthopedics and fracture. $8^{\text {th }}$ edition; London: Arnold, a member of the Hodder Headline Group; 2001. p: 422, 426, 427, 430 and 431.

15. Whitelaw Christine $C$ Transient synovitis: 2006 section 2 of 11 http://www.emedicine.com/PED/topic1676.

16. Swischuk E. Pediatric hip pain, Emergency radiology J. 2002; 3:219-221.

17. Luhmann J, Johns A, Schootman M, Gordon J., Schoenecker L. Luhmann D. Differentiation between septic arthritis and transient synovitis of the hip in children with clinical prediction algorithms. J. Bone Joint Surg. 2004; 86(5): 958-59.

18. Caird S, Flynn John M, Leung Y, Millman E, D'Italia G. Factors distinguishing Septic arthritis from transient synovitis of the hip in the children. A prospective study. J. Bone Joint Surg. 2006; 88:1251.

19. Nigrovic A, Wilking $P, 2007$. Overview of hip pain in childhood. www.uptodate.com. 
20. Brown D, Neumann D. Orthopedic Secrets. $2^{\text {nd }}$ edition. Philadelphia: Hanley and Belfus, INC 1999; 3:14-16.

21. Canale S. Campbell's operative orthopedics. $10^{\text {th }}$ edition. Philadelphia: Mosby, Inc. 2003; p:694.

22. Duthie B, Bently G, Mercer's orthopedic Surgery. $9^{\text {th }}$ edition. New York; Oxford University Press Inc. 1996; p: 584-588.
23. Boon A, Colledge R, Walker R. Davidson principles of medicine. $20^{\text {th }}$ edition. Philadelphia: Elsevier Limited. 2006; p: 319.

24. Bickerstaff DR, Neal LM, Booth AJ, Brennan PO, Bell MJ. Ultrasound examination of the irritable hip. J Bone Joint Surg.1990; 70: 549-553. 